Journal of the Royal Society of Health Promotion 126 (3): 121-127.

\title{
Mental health and arts participation: the state of the art in England
}

Sue Hacking, PhD, Senior Research Fellow, Department of Nursing, University of Central Lancashire, Vernon Research Annexe, 317 Brook, Preston PR1 2HE. Email shacking@uclan.ac.uk. Tel. 01772 893703. Fax )1772 892998

Jenny Secker, PhD, Professor of Mental Health, Institute for Health \& Social Care, Anglia Polytechnic University \& South Essex Partnership NHS Trust, $3^{\text {rd }}$ Floor Ashby House, Bishop Hall Lane, Chelmsford, Essex, CM1 1SQ. Email j.secker@apu.ac.uk, Tel. 01245 493131 ext. 4810. Fax 01245607521

Lyn Kent, Survey Administrator, Institute for Health \& Social Care, Anglia Polytechnic University, $3^{\text {rd }}$ Floor Ashby House, Bishop Hall Lane, Chelmsford, Essex, CM1 1SQ. Email m.kent@apu.ac.uk, Tel. 07976 827534.Fax 01245607521

Jo Shenton, independent artist and researcher, c/o Jenny Secker.

Helen Spandler, PhD, Research Fellow, Department of Social Work, University of Central Lancashire, Harrington Building, Preston PR1 2HE. Email hspandler@uclan.ac.uk. Tel. 01772 893416. Fax 01772892974 
Journal of the Royal Society of Health Promotion 126 (3): 121-127.

Mental health and arts participation: the state of the art in England 


\begin{abstract}
Although participation in arts activity is believed to have important mental health and social benefits for people with mental health needs, the evidence base is currently weak. This paper reports the first phase of a study intended to support the development of stronger evidence. Objectives for the first phase were to map current participatory arts activity, to identify appropriate indicators, and to develop measures for use in the second phase of the research. A survey of participatory arts projects for people with mental health needs aged 16 to 65 in England, identified via the Internet and relevant organisations, was carried out to map the scale and scope of activity and to establish the nature of current approaches to evaluation.
\end{abstract}

The results indicate that the scope of activity, in terms of projects' settings, referral sources, art forms and participation is impressively wide. In terms of scale, however, projects reported low funding and staffing levels that may have implications for the feasibility of routine evaluation in this field. Current approaches to evaluation were limited, but entailed considerable effort and ingenuity, suggesting that projects are keen to demonstrate their benefits. The survey has enabled us to build on the best evaluation practice identified to develop a measure for assessing the mental health, social inclusion and empowerment outcomes of arts participation for people with mental health needs. For the second phase of the study we will work with arts and mental health projects, using the measure alongside qualitative work in a realistic evaluation design, in order to identify the characteristics of effective projects.

Key words: Arts, mental health, social inclusion. 


\section{Introduction}

In 2004, the Social Exclusion Unit (SEU), located in the UK's Office of the Deputy Prime Minister, produced a report addressing social exclusion and mental health ${ }^{1}$. The report identified the causes of exclusion as lying in large part in the stigmatisation of mental ill health and in a focus on medical symptoms at the expense of enabling people to participate in their local communities. Over a third of respondents to the SEU's consultation identified access to recreational activities, including participation in the arts, as essential to promote social inclusion, and promoting access to arts opportunities is a key recommendation of the report. However, it was acknowledged that the evidence base for arts participation is currently weak. As part of a 27-point action plan the Department for Culture Media and Sport (DCMS), in partnership with the Department of Health (DH), was therefore charged with undertaking research to establish the health benefits and social outcomes of participation in arts projects and the characteristics of effective local projects.

Mental health, social inclusion and arts: developing the evidence base is the study commissioned by DCMS and DH in fulfilment of that brief. It builds on a comprehensive literature review undertaken by the Centre for Arts and Humanities in Health and Medicine at the University of Durham ${ }^{2}$. The twin aims of the study are to carry out an evaluation to assess the mental health and social inclusion outcomes of arts participation, and in doing so to develop an evaluation tool for routine use by participatory arts and mental health projects. Specific objectives are to identify appropriate indicators of mental health and social inclusion outcomes, to develop evaluation measures based on those indicators, and to use the measures, alongside qualitative work, in a realistic evaluation design ${ }^{3}$, in order to identify the characteristics of effective participatory arts and mental health projects. The study relates to 
participatory arts and mental health work in England with people with mental health needs aged 16 to 65 and does not therefore include art therapy. The research is being carried out in two phases. The first phase, reported here, comprised a survey of arts and mental health projects in England to map the range of activity, establish what evaluation data projects already collect, and develop indicators and measures for use in the second phase of the study. Ethics approval for the first phase was granted by the Oxford A Multicentre Research Ethics Committee.

\section{Key concepts for the study}

Since the ideas we are investigating for the study are far from uncontroversial, we have adopted working conceptualisations based on reviews of the arts and health, mental health promotion and social inclusion literatures.

Where mental health is concerned, we found the model put forward by Downie and colleagues ${ }^{4}$ helpful. Crosscutting axes, representing low to high levels of wellbeing and ill health respectively, allow us to locate individuals in one of four quadrants. Importantly, this enables us to see that people with mental health needs can nevertheless aspire to mental wellbeing, in the same way that people with a physical impairment can aspire to good physical health. We have used the term mental health needs because of the contentious and problematic nature of terms used to refer to people who use mental health services. We agreed that it was a less stigmatising and pathologising term which emphasises that people have specific mental health related needs that arts projects may be able to meet. It is precisely in identifying the ways that arts participation might meet such needs that we are interested. Similarly, we have deliberately avoided focusing on psychiatric diagnoses because 
they are also rejected by many people with mental health needs, and by some arts and mental health practitioners. These decisions were consistent with the aim of involving as many arts and mental health projects as possible in the first phase of the study, rather than alienating projects for which a medical model of mental health is antithetical.

The social inclusion literature suggests it is helpful to separate out the concepts of exclusion and inclusion. Whereas tackling exclusion involves removing structural barriers to participation in society for excluded groups $s^{5,6,7}$, for example barriers to employment or education, promoting inclusion should involve a radical shifting of social attitudes to difference ${ }^{1,8,9}$, rather than simply attempting to enable people to fit into an unwelcoming society $^{10,11,12}$. In this respect ideas relating to social capital are useful ${ }^{13}$. While bonding capital is described as connection and contact amongst people who share similar characteristics, bridging capital involves connecting with people unlike ourselves in the wider community. In relation to social inclusion, the development of bridging capital is more likely to promote inclusion. However, bonding capital may play a part relating to a further key concept for the study, that of progress or 'distance travelled' towards other outcomes ${ }^{14}$. Thus for excluded groups, connection with people who have similar needs or experiences may represent a first step towards wider social connections.

'The idea of 'distance travelled' was developed in the context of European Social Fund evaluations to capture progress towards outcomes such as entry to the labour market, ${ }^{14}$ and also provides a useful link between mental health and social inclusion outcomes. In particular, wellbeing outcomes reported from previous arts and health studies ${ }^{15}$, such as high levels of self-esteem, confidence and enjoyment, may represent progress or distance travelled 
towards both social inclusion outcomes such as employment or education, and health outcomes including lower levels of mental ill health and service use $\mathrm{e}^{15}$.

\section{Methods}

A number of methods were used to identify as full a range of relevant projects as possible to invite to participate in the survey. As a first step, Internet searches for 'arts' and 'mental health' were carried out. We also followed up established national and regional networks, mailing lists and databases, 'snowballing' the information we gathered through other projects and word of mouth. The links we made were followed up until there was sufficient overlap in the projects identified for us to be reasonably confident we had exhausted these sources.

At the same time, we contacted a wide range of relevant national and local organisations to ask for help in publicising the study. For these organisations we enclosed a shorter briefing about the study inviting relevant projects to contact us, and asked the organisations to disseminate the briefing for us. This they did via their websites, newsletters and mailing lists.

Each project we identified through these means was sent an introductory letter explaining the research, inviting participation and asking them to circulate our letter to other relevant projects of which they were aware.

\section{Survey questionnaire}

In developing the survey questionnaire we drew on previous arts and health surveys ${ }^{16,17,18}$ to identify useful lines of questioning, and devised further questions to address the study 
objectives where relevant issues had not previously been covered. The questionnaire examined nine main topics:

- the demographic groups with which projects were working

- their funding and staffing levels

- the art forms used

- the settings in which projects worked

- referral sources

- number of participants and the method of participation adopted

- intended outcomes

- the data collected about outcomes, and any evaluation measures used.

Most questions could be answered by ticking a box, though space was also included for 'other' responses that did not fit the categories provided, and for comments if projects wished to add to their responses. Where projects indicated that they were evaluating their work, we asked for copies of the forms or measures they used.

Four projects with which we had contact during the process of setting up the study agreed to pilot the questionnaire for us and it was amended in light of their helpful comments and suggestions. A copy of the questionnaire is available from the corresponding author.

\section{Data collection}

Electronic and postal versions of the questionnaire were produced and where possible it was mailed electronically. Projects were asked to return the questionnaire within three weeks. At the end of this period a reminder was sent to projects that had not yet responded, followed by 
a final reminder around one week later. At this stage, projects that had not responded were contacted by telephone. Although time consuming, this proved valuable in almost doubling the response rate. As questionnaires were returned responses were entered on an Access database to facilitate analysis.

\section{Data analysis}

The process of analysing the survey responses involved 'cleaning' the data followed by thematic categorisation. As an example of cleaning, many projects had ticked more than one box on single answer questions and we used this information to add multiple answer categories to those questions. Where it was possible, category responses were checked for reliability across a project's responses by triangulation with similar or related questions. Where evaluation was concerned, in addition to categorising projects' responses about whether they routinely evaluated their work, we analysed the forms and measures they sent us in order to ascertain the range of methods used and issues covered.

Although we had originally thought it might be possible to develop a typology of participatory arts and mental health projects on the basis of the survey results, this was not possible as no single way of categorising projects proved watertight. The majority of projects were clearly hybrid in nature, operating flexibly and supported by a variety of funding sources. For this reason the results are presented for all responding projects rather than by project type.

\section{Results}


We are unable to calculate a precise response rate to the survey because some organisations and individuals to whom we sent questionnaires copied it to others. Our best estimate is that of around 230 questionnaires distributed 116 were returned, a response rate of $50 \%$.

Of the projects described in the 116 responses received, 102 met the criteria of offering participatory arts activity to adults between the ages of 16-65 with mental health needs. It is difficult to be sure how representative this sample is and it may be that smaller projects are under-represented since the type of projects that were able to respond to our questionnaire in the relatively short space of time available were likely to be more established with higher staffing levels. Nevertheless, we are fairly confident that the responding projects offer a representative sample of these more established projects from which to draw some comparisons. The 102 projects did not all answer every question and the response rate for each question considered therefore varies as noted below.

\section{The scale of participatory mental health and arts provision}

Projects' responses to four questions about funding levels, staffing levels, length of time established and numbers of participants enabled us to gain an impression of the scale of arts and mental health provision in England, at least for the more established projects that comprised our sample.

We asked projects for an estimate of their income for the last 12 months, having assumed that this would be fairly straightforward. In the event, only half the responding projects were able to provide an estimate. The impression from those that were able to do so is that funding 
levels varied greatly over time and could depend in part on opportunistic bids, even where a substantial proportion of income came from established sources.

Additionally, it was clear from responses to questions about staffing levels that projects run as part of statutory sector provision received not insignificant funding 'in kind', particularly staff salaries provided by the host organisation, that was not included in their response. In order to develop a more accurate idea of funding levels nationally per 100 projects, we therefore compared projects' stated annual income with the staffing levels they reported. Where there were obvious discrepancies we calculated the in kind support associated with staff salaries and on costs on the fairly low assumption of an average annual salary of $£ 20,000$ full time equivalent ${ }^{19}$.

The declared funding from the $50 \%$ of responding projects totalled almost $£ 2 \mathrm{~m}$. If these projects were reasonably representative, a funding level nationally of $£ 4 \mathrm{~m}$ per 100 projects would be assumed. Taking into account our staffing cost calculation, however, we estimate that for the more established projects that responded to the survey the funding level is in the region of $£ 7 \mathrm{~m}$ per 100 projects.

Turning to the staffing level responses themselves, we asked projects how many people worked for their project on a part-time, full time, freelance/sessional and volunteer basis. Only six projects were not able to provide this information. Table 1 shows the total number of paid staff and volunteers across the 96 responding projects.

Table 1 about here 
Although projects' responses about funding suggest a patchwork of complex arrangements, responses to a question about the length of time they had been operational do indicate a degree of stability, supporting our impression that such projects were more likely to return a questionnaire. Most projects (92 of 94 that responded to this question) indicated that they had been established for over a year and more than half (54) had been established for over five years. The average was eight years within a range of a few months to as long as 30 years.

Of 97 projects that responded to a question about the number of participants engaged in their project each week, 19 told us they offered a series of sessions or workshops in which participation varied. We therefore calculated the average level of participation in these sessions. The range was very wide, from as few as five participants each week to as many as 300 at one project, with an average of 40 . Around a third (30) of the projects reported having ten or fewer participants each week. Most commonly participation ranged between ten and 30 people (36 projects). In total, projects' responses indicate that around 3,900 people with mental health needs were participating in arts project activity each week.

\section{The scope of provision}

Responses to questions about projects' settings and referral sources provide a broad impression of the extent to which provision related to healthcare or to other contexts. Questions about the art forms used and about project participants enabled us to assess the range of activity provided and for whom. 
Projects were asked to indicate the setting in which they worked on a list including community, healthcare, social services, integrated (health and social services), education and specialist arts settings. All 102 projects were able to respond to this question, many indicating that they worked in more than one setting. Community settings were most common (48 projects), followed by healthcare (38) and specialist arts settings (36). Fewer projects operated in social services (24), education (19) or social service (10) settings.

Most of the 100 projects that responded to the question about referrals accepted referrals from multiple sources, although 12 accepted referrals only from specialist mental health services and four only from primary care health services. Table 2 shows the number of projects accepting referrals from each source identified.

\section{Table 2 about here}

All 102 projects responded to the question about art forms and between them they offered participants a vast range of art activities. The most common were visual arts in the form of drawing and painting (77\%), but craft (60\%) and writing (59\%) were also very common, as were exhibition (55\%) and photography (53\%). Most projects offered more than one art activity, with an average of ten and a range from one to 20 or more, although projects offering such an extensive number did not offer them all concurrently.

Questions relating to project participants concerned the proportions of male and female participants, their ethnic background and their mental health needs. Overall, the projects appear to be working with slightly more women than men ( $56 \%$ on average). However, the range was very wide, from as low as two percent at one project to one women-only project. 
Table 3 compares the responses of 95 projects regarding ethnicity with national census data. As can be seen, the projects appeared to be working with above average numbers of people from minority ethnic groups. Sixteen projects specified their main ethnic groups as 'other' and they detailed very diverse populations, including Spanish speaking, Eastern European, Australian, Iranian, Greek, Jewish and Vietnamese people as well as Travellers.

\section{Table 3 about here}

Most projects did not work only with people with mental health needs. Over half (45) worked with people from the wider community as well as people with mental health needs. A further 35 projects worked with people with other identified needs, including learning disabilities (17), physical disabilities (12), long term illness (4) and older people (2).

\section{Models of provision}

Questions relating to the models adopted in providing arts and mental health participation for people with mental health needs concerned the methods of participation adopted and the extent to which people with experience of using mental health services were involved in running projects. 
Projects were asked to select the method adopted for participant involvement from a list of descriptions adapted from a previous review of arts based projects ${ }^{17}$. The descriptions encompassed five methods:

- Instruction/education: an artist, instructor or someone in a similar role directs or educates project participants

- Guidance: project participants motivate themselves to produce their own art works, with guidance where necessary

- Collaboration on given project: project participants work together on a project decided by an artist, instructor or someone in a given role

- Collaboration decided by participants: project participants cooperate to decide on a project and work together on it

- Creation of events: professional artists work with a project group to create a festival, pageant or other event.

One hundred projects responded to the question. The responses indicated that directed methods were most common (48 projects using instruction/education or collaboration on a given project), with participant-led methods in second place (33 projects using guidance or collaboration decided by participants). The creation of festivals and other events tended to be used by 18 projects that adopted more than one method because they were running different programmes at different times, or several programmes concurrently with different groups.

All 102 projects responded to the question about service user involvement. At over half the projects $(57 \%)$ current or former service users helped run the project as volunteers. In almost half $(44 \%)$, they were committee members and in a similar proportion (42\%) they were 
employed as staff members. Only 15 projects did not appear to involve people with experience of using services in running the project.

\section{Intended outcomes and evaluation}

We asked projects to select the outcomes they intended their work to have for participants from a given list and to then rank the three most important. Amongst the 101 projects that responded, the most common and most important outcomes, agreed by more than $90 \%$ of the projects, were:

- improved self-esteem

- improved quality of life

- personal growth in the sense of a transformation of identity

- increased artistic skill.

Although most projects hoped for and worked towards social inclusion outcomes such as increased employment opportunities and health related outcomes such as reduced use of services or medication, none ranked these as the most important outcomes.

Of 99 projects that responded to the question about evaluation $59(61 \%)$ indicated that they routinely assessed the outcomes of their work. A further 24 projects $(25 \%)$ had carried out an evaluation in the past, and eight were currently doing so. Only eight projects had never carried out an evaluation.

Thirty-nine projects sent us examples of the various forms they routinely used for evaluation. Like previous reviews $s^{2,18,20}$, our analysis of these suggests that projects are keen to 
demonstrate the benefits of their work but are struggling in some respects to find ways of doing this. Only two projects indicated that they used a standardised, validated outcome measure at more than one point in time, although a third project used a range of scales that appear to be derived from standardised measures of well-being and self-esteem. Perhaps unsurprisingly, all three projects were located within or primarily funded by the health sector, where there are stronger traditions of formal evaluation than in other sectors.

Of the other methods in use alongside or instead of standardised measures, the great majority (25) comprised participant-completed questionnaires presumably developed by the projects concerned. In 23 cases, the forms were completed at one point in time, most commonly at the end of participants' involvement with the project. Only two projects asked participants to complete their forms at the beginning of and in later stages of their involvement with the project.

Other methods used by projects alongside or in addition to participant-completed questionnaires included:

- monitoring forms completed by workers (usually artists) after each session or series of sessions (9 projects)

- qualitative methods such as interviews, group discussions, diaries, observation and case studies ( 5 projects)

- recording and review of participants' goals (3 projects). 
One project had commissioned an innovative arts-based evaluation within which creative techniques were used alongside more conventional evaluation methods in an attempt to elicit and monitor changes in participants' health and wellbeing.

In order to examine what sort of outcomes were evaluated we used three categories derived from our literature review to group the content of projects' forms:

- distance travelled outcomes, including bonding social capital, confidence, selfesteem, empowerment, enjoyment, learning/skills gained and pride in the work produced.

- health outcomes, including mental health status, service and medication use

- social inclusion outcomes, including bridging social capital, employment and education outcomes, and future aspirations related to employment and education.

Table 4 shows the number of projects evaluating their work within the three categories and their sub-categories (projects might be evaluating more than one dimension within each main category).

Table 4 about here

\section{Discussion}

The survey responses indicate that participatory arts and mental health activity is a vibrant strand within the wider English mental health economy. There were indications in projects' responses, however, that the wide range of activity reported is achieved with limited resources. Even projects with established funding sources appeared to be relying on 
opportunistic bids to maintain their activity and our estimated national annual spend of $£ 7$ million per 100 projects is something of a drop in the ocean compared to the cost of poor mental health in England, estimated at $£ 77$ billion each year ${ }^{21}$. Average staffing levels were also low and the figures may be an overestimate since smaller projects or those with funding or staffing difficulties may have been less likely to return a questionnaire. However, the low staffing levels reported have to be set against the extensive use of volunteers, which may be more in keeping with the participatory approach and intended outcomes of many projects than employing higher numbers of paid staff. Funding and staffing levels notwithstanding, it appeared that the projects in our sample had achieved a measure of stability, with many established for eight years or more. In terms of projects' capacity to routinely evaluate their work stability in this respect is important. However, to engage in routine evaluation, projects may also need greater capacity than our survey suggests is the case in respect of funding and core staffing levels.

Despite the relatively low funding and staffing levels documented by their responses, the projects in our sample were offering an impressive variety of arts activities to almost 4,000 people with mental health needs each week. The range of sources from which referrals were accepted was wide at most projects, with self-referral second only to specialist mental health services in frequency, suggesting a high degree of accessibility. That most projects worked with people from the wider community as well as with people with mental health needs is of especial interest in relation to the promotion of social inclusion through developing bridging capital.

In other respects too, the projects were succeeding in areas where many mental health providers struggle. They were reaching above average proportions of people from Black and 
minority ethnic communities and levels of service user involvement in the running of projects were high. The importance of these achievements cannot be underestimated in the context of major policy thrusts in relation to both Black and minority ethnic mental health ${ }^{22}$ and service user involvement in services ${ }^{23,24,25}$.

The impression from some of the arts and mental health literature ${ }^{26}$ is that the use of standardised outcome measures may be antithetical to arts projects' aims and objectives. While this may go some way to explaining why only three projects in our sample were using standardised measures, the majority of projects that were evaluating their work were trying to obtain some kind of standardised information, suggesting that there may be a greater willingness to go down this route than thought.

Certainly the methods projects have designed for themselves demonstrate considerable effort and ingenuity. That the majority are participant-completed questionnaires is unsurprising, since these are relatively quick and inexpensive to use, and can provide projects with useful feedback relating to their own aims and objectives and those of funders. There are, however, clear disadvantages to this approach, not least that projects up and down the country were 'reinventing the wheel' in designing their own ways of measuring similar constructs such as enjoyment or self-esteem.

That most projects were evaluating their work at only one point in time is also problematic since this does not allow for the measurement of change over time. Even where projects were using pre-and post-intervention measures, it is difficult to attribute any changes to the projects' work because these could be the result of other factors. However, establishing a control or comparison group is unlikely to be feasible for projects without the assistance of 
external researchers. More practically, one project used a standardised questionnaire to assess change, together with further questions directly asking participants to indicate whether the project had made a difference in relation to that aspect of their lives. We suggest that the way forward for routine evaluation lies in this direct approach.

Of the other methods being used, qualitative methods such as observation, interviews and group discussions are valuable in exploring participants' experiences and perceptions of their involvement in artistic work but these methods do not easily lend themselves to routine evaluation. Where they have been used it tends to be in the context of commissioned, external evaluations that are inevitably too expensive and time consuming for routine use. We are not suggesting that this approach should never be used. On the contrary, where funding is available an external evaluation of this kind can illuminate and augment projects' routine evaluations and it would be heartening to see more work of this kind being funded.

Where evaluation content was concerned, it was clear that the various dimensions of what has been termed "distance travelled" ${ }^{14}$ towards social inclusion and health outcomes were both of greatest importance to projects in terms of their intended outcomes, and amongst the outcomes they most frequently evaluated. Some of these dimensions, such as enjoyment, learning/skills gained and pride in the work produced, can obviously only be measured postintervention, but for others, such as self-esteem and empowerment, there are existing published measures that could be used in a pre- and post-evaluation design, including a User Empowerment Measure, developed with input from mental health service users, that is particularly relevant ${ }^{28}$. 
Fewer projects were evaluating outcomes directly related to health and social inclusion, in part no doubt because these were not amongst their most important intended outcomes, a finding consistent with previous research ${ }^{18}$. The two standardised health measures already in use at two projects were the Hospital Anxiety and Depression (HAD) scales and Clinical Outcomes in Routine Evaluation (CORE). Of these we suggest more widespread use of CORE would be useful, because this is a relatively brief measure of general mental health and wellbeing. This does not mean of course that the HAD is not useful where reducing levels of anxiety and depression are specific project aims.

Social inclusion was clearly more problematic for projects to measure. Although 16 projects were attempting to assess relevant dimensions, in ten cases this was based on participants' future aspirations rather than their actual experience. Our investigations indicate that the development of validated, standardised measures of social inclusion is at an early stage but we identified a number of sources for useful questions ${ }^{9,15}$ on which we will draw to design a measure for the second phase of our study.

\section{Conclusions}

As far as the scope of participatory arts and mental health activity in England is concerned, our survey indicates that the state of the art is impressive in terms of the numbers of people reached, the range of art forms available, the breadth of referral sources and involvement of the wider community. Particular achievements relate to the participation of people from Black and other minority ethnic groups and service user involvement in running projects. 
In terms of scale, the state of the art may be less robust, with low reported funding and staffing levels that have implications for the feasibility of routine evaluation. Evaluation itself, not unexpectedly, appears to be limited. However, the great majority of projects were evaluating their work in some way and were clearly keen to demonstrate their benefits.

For the second phase of the study we are building on the survey results and literature review to develop an evaluation questionnaire incorporating the CORE, the User Empowerment Measure and our own social inclusion measure. The outcomes study will begin in October 2005, with qualitative work starting in spring the following year. The final report from the study will be available towards the end of 2006. 
Journal of the Royal Society of Health Promotion 126 (3): 121-127.

\section{References}

${ }^{1}$ ODPM Mental Health and Social Exclusion. London, Office of the Deputy Prime Minister, 2004.

${ }^{2}$ White M. and Angus J. Arts and Adult Mental health Literature Review. Centre for Arts and Humanities in Health and Medicine, Durham, University of Durham, 2003.

${ }^{3}$ Pawson R. and Tilley N. Realistic Evaluation. London, Sage Publications., 1997.

Angus J. A Review of Evaluation in Community-based Arts for Health Activity in the UK.

Centre for Arts and Humanities in Health and Medicine, Durham, University of Durham, 2002.

${ }^{4}$ Downie R., Fyfe C. and Tannahill A. Health Promotion: Models and Values. Oxford, Oxford University Press, 1990.

${ }^{5}$ Department of Social Security Opportunities for All: Tackling Poverty and Social Exclusion. A Summary of the First Annual Report. London, The Stationery Office, 1999.

${ }^{6}$ Joseph Rowntree Foundation Findings: Poverty and Social Exclusion in Britain. York, Joseph Rowntree Foundation, 2000.

${ }^{7}$ Jermyn, H. (2001) The Arts and Social Exclusion: a review prepared for the Arts Council of England. London, Arts Council England, 2001. 
${ }^{8}$ Dunn, S. Creating Accepting Communities - Report of the MIND Inquiry into Social Exclusion and Mental Health Problems. London, MIND, 1999.

${ }^{9}$ Bates P. Reviewing Measures of Social Inclusion. Nottingham, National Development Team, 2005.

${ }^{10}$ Bates P. and Davis F. Social Capital, Social Inclusion and Services for people with learning disabilities. Disability and Society 2004; 19:3: 195-207.

${ }^{11}$ Wallcraft J. Social inclusion, strategies for living and recovery, 2001. Available online at http://www.scmh.org.uk/website/threaded_discussion.nsf/0/17dbdfb0f19eb63c80256a71002c 59c4?OpenDocument (Accessed 20 September 2005).

12 Jermyn, H. The art of inclusion. London, Arts Council England, 2004.

${ }^{13}$ Putnam R. Bowling alone: America's declining social capital. Journal of Democracy 1995; 6: $1: 65-78$.

${ }^{14}$ Dewson S., Eccles J., Tackey N. and Jackson A. (2000) A Guide to Measuring |Soft Outcomes and Distance Travelled. Sheffield, Department for Education and Skills, 2000.

${ }^{15}$ Matarasso F. Use or Ornament? The Social Impact of Participation in the Arts. Stroud, Comedia, 1997. 
Journal of the Royal Society of Health Promotion 126 (3): 121-127.

${ }^{16}$ Health Development Agency Art for Health: A Review of Good Practice in CommunityBased Arts Projects and Interventions which Impact on Health and Well-being. London, Health Development Agency, 2000.

${ }^{17}$ Health Development Agency Art for Health: A Review of Good Practice in CommunityBased Arts Projects and Interventions which Impact on Health and Well-being. Summary Bulletin. London. Health Development Agency, 1999.

${ }^{18}$ Angus J. A Review of Evaluation in Community-based Arts for Health Activity in the UK. Centre for Arts and Humanities in Health and Medicine, Durham, University of Durham, 2002.

${ }^{19}$ Office for National Statistics Average weekly earnings for public sector workers Quarter 1, 2005. Available on line at http://www.statistics.gov.uk/downloads/theme_labour/AWE_Tables_Updated.xls (Accessed 22 September 2005)

${ }^{20}$ Ruiz J. Literature review of the evidence base for culture, the arts and sport policy. Edinburgh, Scottish Executive, 2004.

${ }^{21}$ Sainsbury Centre for Mental Health Economic and Social Costs of Mental Illness in England. London, Sainsbury Centre for Mental Health, 2003. 
Journal of the Royal Society of Health Promotion 126 (3): 121-127.

${ }^{22}$ Department of Health Delivering race equality in mental health care: an action plan for reform inside and outside services and the government's response to the independent inquiry into the death of David Bennett. Department of Health, London, 2005.

${ }^{23}$ Department of Health National Service Framework for Mental Health - Modern Standards and Service Models. Department of Health, London, 1999.

${ }^{24}$ Department of Health The NHS Plan: A Plan for Investment, a Plan for Reform. Department of Health, London, 2000.

${ }^{25}$ Department of Health Creating a Patient-led NHS: Delivering the NHS Improvement Plan. Department of Health, London, 2005.

${ }^{26}$ Smith T. An Evaluation of Sorts - Learning from Common Knowledge. Centre for Arts and Humanities in Health and Medicine, Durham, University of Durham, 2003.

${ }^{27}$ Schafer T. Empowerment: towards a participatory model for the evaluation of the empowering therapeutic environment. Mental Health Care 2000; 3: 7: 233-237. 
Journal of the Royal Society of Health Promotion 126 (3): 121-127.

\begin{tabular}{lcc}
\hline & $\begin{array}{c}\text { No. } \\
\text { staff }\end{array}$ & $\begin{array}{c}\text { No. of projects with } \\
\text { each staff category }\end{array}$ \\
& 97 & 40 \\
\hline Full time staff & 100 & 39 \\
Part time staff (over 15 hours) & 106 & 42 \\
Part time staff (under 15 hours) & 275 & 54 \\
Sessional staff & & 59 \\
& 286 & 96 \\
Volunteers & 96 & \\
Total no. of projects responding & 96 & \\
\hline
\end{tabular}

Table 1. Project staffing 


\begin{tabular}{|l|c|}
\hline Source & No. of projects \\
\hline Specialist mental health services & 87 \\
\hline Self-referral & 75 \\
\hline Primary care services & 66 \\
\hline Voluntary \& community agencies & 57 \\
\hline Social services & 59 \\
\hline Informal carers & 41 \\
\hline
\end{tabular}

Table 2. Referral sources 
Journal of the Royal Society of Health Promotion 126 (3): 121-127.

\begin{tabular}{lll}
\hline & $\begin{array}{ll}\text { Census 2001 } \\
(\%)\end{array}$ & $\begin{array}{l}\text { Arts Projects } \\
(\% \mathrm{n}=95)\end{array}$ \\
\hline White & 92.1 & 85 \\
Asian & 4.0 & 8.6 \\
Black & 2.0 & 12.1 \\
Chinese & 0.4 & 5.4 \\
Other & 1.6 & 4.6 \\
All minority ethnic & & \\
groups & 7.9 & 16.0 \\
\hline
\end{tabular}

Table 3. Percentage participation by ethnic group 
Journal of the Royal Society of Health Promotion 126 (3): 121-127.

\begin{tabular}{|l|c|}
\hline Outcome & No. projects \\
\hline Distance travelled & 46 \\
\hline Bonding capital & 4 \\
\hline Enjoyment & 17 \\
\hline Learning / skills gained & 11 \\
\hline Self-esteem, confidence, empowerment & 1 \\
\hline Pride in the work produced & $\mathbf{1 3}$ \\
\hline Health & 7 \\
\hline Mental health status & 6 \\
\hline Service \& medication use & $\mathbf{1 6}$ \\
\hline Social inclusion & 3 \\
\hline Bridging capital & 3 \\
\hline Employment/education & 10 \\
\hline Future hopes, aspirations, intentions & \\
\hline
\end{tabular}

Table 4. Evaluation content 